\title{
Comparison of bone marrow, disseminated tumour cells and blood-circulating tumour cells in breast cancer patients after primary treatment
}

\section{MJ Slade', R Payne', S Riethdorf', B Ward ${ }^{3}$, SAA Zaidi', J Stebbing', C Palmieri', HD Sinnett ${ }^{3}$, E Kulinskaya $^{4}$, T Pitfield ${ }^{5}$, RT McCormack ${ }^{6}, K^{2}$ Pantel $^{2}$ and RC Coombes ${ }^{*}, 1$}

'Department of Oncology, Imperial College, MRC Cyclotron Building, London WI2 ONN, UK; ${ }^{2}$ Institute of Tumor Biology, University Medical Center Hamburg-Eppendorf, Hamburg D-20246, Germany; ${ }^{3}$ Department of Medical Oncology, Imperial College Healthcare NHS Trust, Charing Cross Hospital, Fulham Palace Road, London W6 8RP, UK; ${ }^{4}$ Statistical Advisory Senvice, Imperial College, South Kensington Campus, London SW7 INA, UK; ${ }^{5}$ Veridex LLC, 50- 100 Holmers Farm Way, High Wycombe, HPI 2 4DP, UK; ${ }^{6}$ Veridex LLC, 33 Technology Drive, Warren, NJ 07059, USA

The purpose of this study was to determine whether primary breast cancer patients showed evidence of circulating tumour cells (CTCs) during follow-up as an alternative to monitoring disseminated bone marrow tumour cells (DTCs) by immunocytochemistry and reverse transcriptase (RT)-PCR for the detection of micrometastases. We planned to compare CTC and DTC frequency in low-risk and high-risk patients. We identified two cohorts of primary breast cancer patients who were at low (group II, $T, N_{0}, n=18$ ) or high (group III, $>3$ nodes positive (with one exception, a patient with two positive nodes) $n=33$ ) risk of relapse who were being followed up after primary treatment. We tested each cohort for CTCs using the CellSearch system on I-7 occasions and for DTCs by immunocytochemistry and RT-PCR on $1-2$ occasions over a period of 2 years. We also examined patients with confirmed metastatic disease (group IV, $n=12$ ) and 2 I control healthy volunteers for CTCs (group I). All group I samples were negative for CTCs. In contrast, 7 out of I 8 (39\%) group II primary patients and 23 out of 33 (70\%) group III patients were positive for CTCs $(P=0.042)$. If we count only samples with $>$ I cell as positive: 2 out of I 8 (I I\%) group II patients were positive compared with 10 out of $33(30 \%)$ in group III $(P=0.174)$. In the case of DTCs, I out of I $3(8 \%)$ group II patients were positive compared with 19 out of $27(70 \%)$ in group III $(P<0.00 \mathrm{I})$. Only 10 out of $33(30 \%)$ patients in group III showed no evidence of CTCs in all tests over the period of testing, compared with I I out of I $8(6 \mid \%)$ in group II $(P=0.033)$. A significant proportion of poor prognosis primary breast cancer patients (group III) have evidence of CTCs on follow-up. Many also have evidence of DTCs, which are more often found in patients who were lymph node positive. As repeat sampling of peripheral blood is more acceptable to patients, the measurement of CTCs warrants further investigation because it enables blood samples to be taken more frequently, thus possibly enabling clinicians to have prior warning of impending overt metastatic disease.

British Journal of Cancer (2009) 100, I60-166. doi:10. I038/sj.bjc.6604773 www.bjcancer.com

Published online 25 November 2008

(c) 2009 Cancer Research UK

Keywords: micrometastasis; detection; disseminated; circulating; CellSearch

Breast cancer is the most common cancer among women in the United States and Europe. Although mammographic screening and the judicious use of adjuvant systemic therapy have improved the survival from this disease, many patients still relapse and develop metastatic disease. Metastases inevitably result in the death of the patient.

Over the past 10 years, long-term follow-up of patients in trials designed to evaluate adjuvant endocrine or cytotoxic chemotherapy has indicated that cure can be achieved in a proportion of

*Correspondence: Professor RC Coombes, Department of Oncology, Imperial College School of Science, Medicine and Technology, 8th Floor, MRC Cyclotron Building, Du Cane Road, London WI2 ONN, UK; E-mail: c.coombes@imperial.ac.uk

Received 6 November 2008; revised 8 October 2008; accepted 16 October 2008; published online 25 November 2008 patients by these treatments. For this reason, considerable efforts have been made to discover a means of monitoring these patients, in the hope of finding a test that would distinguish those who need further sequential adjuvant therapy from those for whom this treatment would not be necessary. This has become particularly important on account of our recent studies showing that 'interval' or 'switching' techniques improve disease-free (Coombes et al, 2004) and overall survival (Coombes et al, 2007).

Several studies have now shown that the presence of occult metastases in the bone marrow identifies a population of patients at high risk for recurrence (Redding et al, 1983; Cote et al, 1988; Diel et al, 1996; Mansi et al, 1999; Braun et al, 2000c; Wiedswang et al, 2003; Naume et al, 2004). In our original study (Neville et al, 1983), the presence of bone marrow occult metastases was correlated with tumour stage and vascular invasion, both of which are known predictors of poor prognosis. Other studies of note are Diel et al (1996) and Braun et al (2000b) who analysed bone 
marrows from 727 and 552 patients, respectively, using immunocytochemistry (ICC). Both these studies have shown that the occult bone marrow metastases were associated with larger tumour size, lymph mode involvement and high-grade tumour. The presence of micrometastases in bone marrow at surgery has been shown to be an independent prognostic factor in 817 breast cancer patients (Wiedswang et al, 2003). In a pooled analysis of 4703 patients with stages I, II or III breast cancer with 10-year follow-up (Braun et al, 2005), micrometastases at diagnosis were detected in $30.6 \%$ of patients. Those patients with micrometastases had larger tumours and higher histological grade and more frequent lymph node metastases and hormone receptor-negative tumours. This study shows that the presence of micrometastases in the bone marrow at the time of diagnosis of breast cancer was an independent predictor of a poor outcome and is associated with poor prognosis.

In studies from our laboratory and from others, it has been shown that it is possible to detect residual disseminated bone marrow tumour cells (DTCs) in the bone marrow, and circulating tumour cells (CTCs) in the peripheral blood during follow-up. However, the number of cells in the bone marrow is small even after using the best available techniques (i.e., using a pancytokeratin antibody (A45-B/B3), which is well characterized for DTC studies (Braun et al, 2000b)) for staining $2 \times 10^{6}$ cells and analysing automatically. On account of the difficulties inherent in subjecting patients to regular bone marrows, as well as the small number of cells detected in primary patients with no evidence of overt metastases, such tests have been difficult to apply in routine clinical practice. Furthermore, until recently, the peripheral blood has been shown to be generally negative for CTCs in all but a minority of patients, with most series showing $1-5 \%$ of patients found to be positive (Schoenfeld et al, 1997; Slade et al, 2005).

Many groups have attempted to develop a reproducible methodology for CTC detection to improve the detection rate. One of these is the CellSearch ${ }^{\mathrm{TM}}$ (Veridex LLC, Warren, NJ, USA) system with which Cristofanilli et al (2004) carried out a study of 177 patients with metastatic breast cancer. The results from this approach indicated that approximately $70 \%$ of patients with metastatic breast cancer have $>1 \mathrm{CTC} / 7.5 \mathrm{ml}$ of peripheral blood. They also found that patients with five or more CTCs per $7.5 \mathrm{ml}$ of blood had a significantly worse progression-free and overall survival than patients with $<5$ cells per $7.5 \mathrm{ml}$ of blood (progression-free survival was 2.1 vs 7.0 months and overall survival was 8.2 vs 18 months). It has subsequently been shown (Hayes et al, 2006) in this group of patients that elevated CTCs at any time during therapy are an accurate indicator of rapid disease progression and mortality.

We therefore decided to perform a pilot study to determine whether monitoring for CTCs using the CellSearch system was comparable with our current micrometastatic monitoring system using ICC and reverse transcriptase (RT) - PCR of bone marrow samples. This was performed in a group of patients on follow-up after a diagnosis of breast cancer, and none of them had evidence of overt metastases.

\section{MATERIALS AND METHODS}

\section{Patients}

The study was approved by each local ethics committee and conducted in accordance with the declaration of Helsinki and all patients gave written informed consent. Samples were blinded for analysis and patients understood that the results would not be made available to them. Patients diagnosed with early stage breast cancer, who were on routine follow-up, were invited to take part in the study. All women were attending local hospitals in the West London Cancer Network. All patients had previously histologically confirmed primary breast cancer and no evidence of distant metastases on chest radiology, bone scanning or liver ultrasound. It was not possible to compare the two sampling sites (i.e., blood and bone marrow), as the samples were not taken at identical time points for ethical reasons.

\section{Breast cancer patients}

To have a group of patients who were at very low risk of having recurrence in the future, we decided to take the subset of patients from our published study (Slade et al, 2005) to include only those patients with $\mathrm{T}_{1} \mathrm{~N}_{0}$ (i.e., those who had a tumour $\leqslant 2 \mathrm{~cm}$ ) and who were node negative (group II) 4-13 years post-surgery. For the high-risk group (group III), we included patients who previously had $>3$ node-positive breast cancer (with one exception, a patient with two positive nodes) and were on follow-up and who had no sign or symptom of recurrence. We examined $3 \times 7.5 \mathrm{ml}$ samples of blood from all of these patients together with the same amount of blood from a cohort of women with no past history of breast cancer (negative control - group I). We repeated the sampling procedure 1-7 times over a 2-year period. As positive controls, we took $1 \times 7.5 \mathrm{ml}$ blood from a group of 12 patients with overt metastatic breast cancer (group IV).

\section{Preparation of bone marrow samples}

The skin was incised before the aspirates were taken to minimise the risk of epithelial contamination. Between 2 and $5 \mathrm{ml}$ of bone marrow was aspirated into syringes primed with preservative-free heparin (Leo Labs, Risborough, UK). Bone marrow samples were prepared as described earlier (Slade et al, 1999; Smith et al, 2000). Ficoll (GE Healthcare, Chalfont St Giles, UK) was used to separate the mononucleocytes; these were counted and aliquoted for ICC on the basis of ideally $6 \times 10^{6}$ cells for each methodology but with a minimum of $3 \times 10^{6}$ cells for each. Those undertaking the ICC were blind to the clinical status and identity of the patients and their earlier assay results.

\section{Immunocytochemistry}

Cells were cytocentrifuged at a concentration of $5 \times 10^{5}$ per cytospin, air dried and stained as described earlier (Pantel et al, 1994; Slade et al, 1999; Smith et al, 2000). A total of six areas were stained, of which four were stained for the presence of cytokeratinpositive cells and two were isotype controls. The primary antibody (A45-B/B3 Micromet, Munich, Germany) directed to a common epitope of cytokeratin (Stigbrand et al, 1998) was used at $2 \mu \mathrm{g} \mathrm{ml}^{-1}$. The rabbit anti-mouse antiserum (Z259; Dako, Hamburg, Germany) and the alkaline phosphatase anti-alkaline phosphatase (APAAP) complex (D651; Dako) were used as recommended by the manufacturer and the reaction developed with new fuchsin. An isotype IgG1 mouse myeloma antibody MOPC-21 (Sigma Aldrich, Poole, UK) served as negative control and the MCF-7 cell line as a positive control (Pantel et al, 1994; Slade et al, 1999; Smith et al, 2000). The cytospins were counterstained with haematoxylin and screened using the Automated Cellular Imaging System (ACIS) (Carl Zeiss Ltd, Welwyn Garden City, UK). Samples that were isotype positive were deemed uninterpretable and therefore excluded from the results.

\section{CellSearch}

Blood, $7.5 \mathrm{ml}$ from the metastatic patients and $3 \times 7.5 \mathrm{ml}$ from the control and primary breast cancer patients, was collected in CellSave ${ }^{\mathrm{TM}}$ preservative tubes (Immunicon, Huntingdon, PA, USA) from patients in London, anonymised, and transported at room temperature to either the Institute of Tumor Biology in Hamburg or the Department of Oncology, Imperial College London for processing within $72 \mathrm{~h}$ of collection as recommended by the 
manufacturer. The CellSearch system was used for the isolation and enumeration of CTCs from each $7.5 \mathrm{ml}$ of blood separately. The CellSearch Epithelial Cell Kit (Veridex) enriches the sample for cells expressing the epithelial-cell adhesion molecule (Ep-CAM) with antibody-coated magnetic beads, and labels the cells with the fluorescent nucleic acid dye 4,2-diamidino-2-phenylindole dihydrochloride (DAPI). Fluorescently-labelled monoclonal antibodies raised against leukocytes (CD45-allophycocyanin) and epithelial cells (cytokeratin 8, 18, 19-phycoerythrin) are used to distinguish epithelial cells from leukocytes. The identification and enumeration of CTCs were performed with the use of the CellTracks Analyzer (Immunicon), a semi-automated fluorescence-based microscopy system that permits computer-generated reconstruction of cellular images. Circulating tumour cells were defined as nucleated cells lacking CD45 and expressing cytokeratin in accordance with the criteria specified by Veridex.

\section{Real-time QPCR}

Real-time QPCR for CK-19 and ABL was performed using the LightCycler $^{\mathrm{TM}}$ (Roche Diagnostics, Mahnheim, Germany). The assay used the LightCycler DNA FastStart SYBR Green 1 kit (Roche Diagnostics) using $2 \mu \mathrm{l}$ of combined dNTPs, Taq DNA polymerase and SYBR Green plus $2.5 \mu \mathrm{l}$ of $\mathrm{cDNA}$ and $0.625 \mu \mathrm{m}$ of primers in a total volume of $20 \mu \mathrm{l}$.

\section{Primers}

CK-19Do

A2N

A4-
CK-19S

\section{5'-GCGGGCAACGAGAAGCTAA-3' 5'-CTCATGCGCAGAGCCTGTT- ${ }^{\prime}$ 5'-CCCAACCTTTTCGTTGCACTGT- $3^{\prime}$ 5'-CGGCTCTCGGAGGAGACGTAGA-3'}

The standard used for quantitation was the artificial construct described earlier (Slade et al, 1999), in the range $10^{1}-10^{4}$ for CK-19 and $10^{3}-10^{6}$ for ABL per $2.5 \mu \mathrm{l}$.

\section{Statistical methods}

Owing to the small numbers, exact two-sided non-parametric tests were used throughout at $5 \%$ level of significance. The exact Pearson $\chi^{2}$-test was used for testing association of two categorical variables, the Mann-Whitney test for the comparison of continuous variables between the two groups, and the Spearman correlation for correlations of two continuous variables.

\section{RESULTS}

To perform this pilot study, we recruited 51 primary breast cancer patients (18 group II $\mathrm{T}_{1} \mathrm{~N}_{0}$ 'low risk' and 33 group III $>3$ nodes positive (with one exception, a patient with two positive nodes) 'high risk' patients) who were on routine follow-up, with no clinical evidence of disease, 4-13 years after diagnosis. No patient had any sign or symptom of metastatic breast cancer. Two control populations were also recruited, 21 non-cancer controls (group I) and 12 metastatic patients (group IV), to confirm earlier results with the CellSearch system (Cristofanilli et al, 2004, 2005; Riethdorf et al, 2007). Overall, 14 patients in group III and one patient in group II were taking adjuvant endocrine therapy. No patient changed treatment during the course of the monitoring period. Patients in group II had one bone marrow sample taken yearly. The higher risk patients in group III had two bone marrows taken 6-12 months apart. All patients had between 1-7 samples of peripheral blood taken (three tubes or $22.5 \mathrm{ml}$ of blood at each time point) for immunocytochemical evaluation using the CellSearch system approximately 6-34 months apart. These patients also had an isotopic bone scan, liver ultrasonography and chest radiology, as well as blood evaluation for full haematological and biochemical screen to exclude overt metastatic disease. All but two patients had no evidence of metastatic disease. For ethical reasons, the non-cancer controls had two blood tests $(15 \mathrm{ml})$ for the CellSearch system and only patient groups II and III had bone marrow aspirates taken. The number of CTCs and DTCs present in blood and bone marrow, respectively, were compared in the low- and high-risk primary breast cancer patient groups.

\section{CTC results}

In the patients with overt metastases, we found CTCs in seven patients; the mean number of cells detected was 51 with a range of $0-301$. Fewer patients (7 out of $18(39 \%)$ ) in group II compared with group III (23 out of $33(70 \%)$ ) had at least one CTC $\left(P=0.042\right.$, exact $\chi^{2}$-test). Results are shown for all patients in Tables 1 and 2 . We then analysed our results taking $>1$ cell as positive: 2 out of $18(11 \%)$ patients in group II $v s 10$ out of 33 $(30 \%)$ in group III were positive using this cutoff point $(P=0.174$, exact $\chi^{2}$-test).

Groups II and III patients were tested for CTCs using the CellSearch system at 1-7 time points. There was no difference in the number of tests between the groups $(P=0.812)$, although the time from diagnosis to the start of testing and the time of intervals between tests were not associated with the results of the CTC tests within the groups ( $P$-values 0.274 and 0.602$)$. Neither oestrogen receptor (ER) or progesterone receptor (PR) status nor tumour size affected the proportion of the CTC-positive tests within each group $(P=0.374$ and $P=0.238)$.

None of the non-cancer controls had any evidence of CTCs. Of the 18 group II patients five $(28 \%)$ were positive at one time point, and two (11\%) at two time points. By contrast, in group III, 13 $(39 \%)$ patients were positive at one time point, six (18\%) at two time points and four (12\%) at three time points.

In all, only 10 out of $33(30 \%)$ patients in group III showed no evidence of CTCs in all tests over the period of testing, compared with 11 out of $18(61 \%)$ in group II $(P=0.033)$. The negative patients may reflect the potentially small number of patients who will not clinically relapse. Two patients developed evidence of overt metastases during the course of the study. Both of these patients had positive results on the CellSearch system, and in each patient, DTCs were detected by ICC in one of the two bone marrows and by QPCR in two of the bone marrows.

The chances of finding positive results did not seem affected by whether or not the patients were receiving endocrine therapy at the time of sampling $(P=0.389$ and $P=0.693$ for groups II and III, respectively).

Over this period of sampling for CTCs, we obtained 68 bone marrow samples for DTC analysis; 13 patients in group II and one patient in group III were tested once, and 27 patients in group III at two time points. Overall, 1 out of 13 patients $(8 \%)$ in group II were positive for DTCs in contrast to the 19 out of 27 positive at least once when tested at two time points in group III $(P<0.001)$. Only 8 out of $27(30 \%)$ patients in group III were negative at both time points, 16 out of 27 were positive once, and 3 out of 27 positive at two time points, but none had two or more cells at both time points (see Tables 1 and 2).

For bone marrow QPCR, none of the 13 patients in group II were positive in contrast to 16 of 27 patients tested at two time points in group III $(P<0.001) ; 16$ were positive at both time points.

We also studied the relationship between the DTC results and the CTC results. Patients consistently negative for DTCs in bone marrow (measured by ICC) can have positive CTCs ( 5 out of 12 in group II and 4 out of 8 in group III), but among the patients with positive DTCs, there is a high proportion of patients with positive CTCs (16 out of $19(84 \%)$ in group III). These numbers were too small to reach statistical significance $(P=0.145)$. 


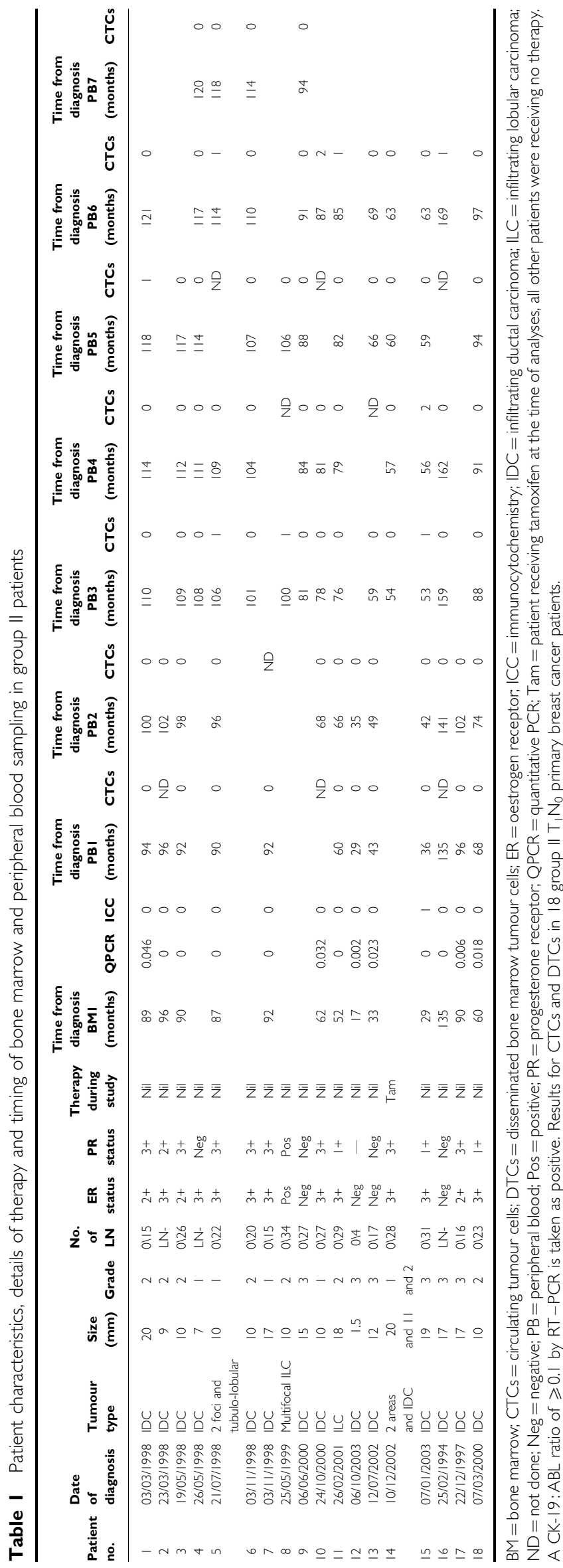

\section{DISCUSSION}

These data indicate that some patients who have had a diagnosis of breast cancer have evidence of micrometastatic breast cancer during follow-up, despite having no clinical evidence of metastases. Seven of $18(39 \%)$ of the $\mathrm{T}_{1} \mathrm{~N}_{0}$, group II patients were found to have CTCs compared with 23 of $33(70 \%)$ of the patients with lymph-nodepositive disease. Although the numbers of patients in this pilot study are small, the results suggest that the likelihood of finding CTCs and DTCs on follow-up is greater in the patients who are at higher risk of recurrence ( $P=0.042$ and $P<0.001$, respectively) and that the numbers of CTCs are greater in the poor-risk patients.

We have previously published the fact that there is occasional evidence of DTCs on follow-up of patients over 4 years after treatment for primary breast cancer (Slade et al, 2005). Most patients show considerable variability. In this pilot study, we have intensively investigated a cohort of patients and found, on the basis of one or two separate tests over a 2-year follow-up period, that many patients show positive tests, sometimes confirmed by the CellSearch test for CTCs. It may be significant that a proportion of patients with bad prognosis on the basis of their tumour histology showed consistently negative results. None of these relapsed with overt disease during the course of the study, compared with two patients in the group with positive results.

There have been few studies in primary breast cancer patients, either at presentation or at follow-up. Wulfing et al (2006) discovered that $50 \%$ of patients had evidence of HER-2-positive cells in the blood and that this correlated with survival. It can be noted that some patients who were initially judged to have HER-2-negative tumours had HER-2-positive CTCs. It can be noted that some patients who were initially judged to have HER-2 negative tumours had HER-2 positive CTCs. A study of 456 primary patients showed that $28 \%$ had $\geqslant 1$ CTC in $3 \times 7.5 \mathrm{ml}$ of blood but the presence of CTCs did not correlate with any prognostic features of the primary tumour (Rack et al, 2006). Studies such as this are necessary in order to determine a cut-off for positivity in primary patients (both this study and ours used a cut-off of a single CTC) with clinical follow-up and also studies in patients with benign breast disease.

Discrepancies between the findings for DTCs and CTCs may be explained either by differences in the methodology of detection (RT-PCR for CK-19 only, as compared with ICC for CK8, 18 and 19 for the DTCs and Ep-CAM enrichment, followed by pancytokeratin staining for CTCs), or because DTCs and CTCs represent two different levels of risk. It has been shown that CTCs have a half-life of 1-2.4h (Meng et al, 2004) and are nonreplicating (Muller et al, 2005) and that these must be replenished by replicating cells from elsewhere. Potentially, this could be the bone marrow; however, the DTCs, when in the bone marrow, are also non-replicating in the majority of primary breast cancer patients (Pantel et al, 1993; Muller et al, 2005). In each case, we have used the best available methodologies for detecting the cells and further studies on a larger cohort of patients along with improvements in assays, for example, CellSearch applied to bone marrow aspirates, may improve the correlation between CTCs and DTCs. With regard to the CTCs and DTCs being biologically and genetically different cells or DTCs in bone marrow being a subset of CTCs circulating in blood, we are currently investigating this using single-cell PCR and microarray analysis.

The most commonly used methods for detection of tumour cells in breast cancer are immunocytochemistry and molecular methods in the form of RT-PCR. There has been extensive research into methods for detection of occult micrometastases in patients before clinical manifestation. To date, bone marrow has been the most common site investigated for micrometastatic organ involvement. This is probably because of easy accessibility and the physiological absence of epithelial cells in the bone marrow, and also because the bone marrow is a homing site and blood is a transition compartment, two different biological compartments 
Table 2 Patient characteristics, details of therapy and timing of bone marrow and peripheral blood sampling in group III patients

$\frac{0}{0}$
$\frac{0}{8}$
$\frac{1}{0}$
$\frac{1}{2}$

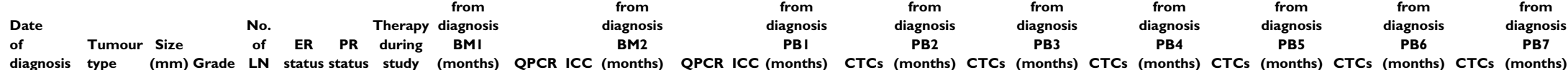

no. diagnosis type (mm) Grade LN status status study (months) QPCR ICC (months) QPCR ICC (months) CTCs (months) CTCs (months) CTCs (months) CTCs (months) CTCs (months) CTCs (months) CTCs

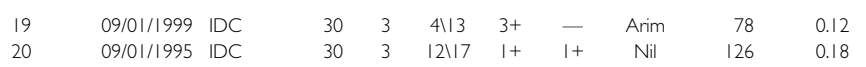

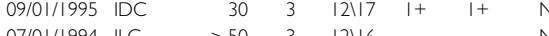

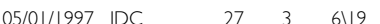

$9 \mathrm{Neg} \mathrm{Neg} N$

09/01/1996 ILC

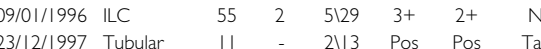

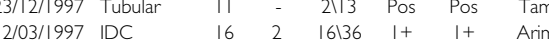
$08 / 01 / 1999$ IDC $\quad 10 \quad 2 \quad 5115$ 3+ $\quad 3+\quad$ Arim $\begin{array}{llllllll}01 / 01 / 1997 & \text { IDC } & 20 & 3 & 8121 & \mathrm{Neg} & \mathrm{Neg} & \mathrm{Nil}\end{array}$

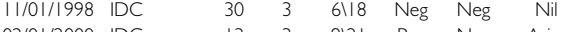

$02 / 01 / 2000$ IDC

05/01/1998 IDC

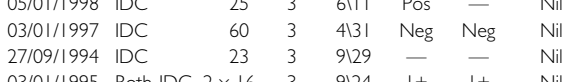

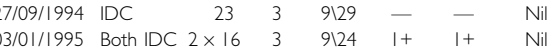

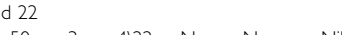

$09 / 01 / 1997$ T2 N

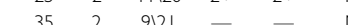

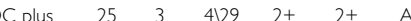

$02701 / 1999$ IDC $\quad 45 \quad 3 \quad 6114$ Pos Pos Arim

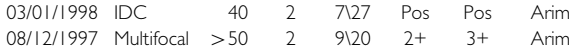

IDC
090141997 TXN4

04/0/1/1998 IDC $\quad 60 \begin{array}{llllll}6 & 2 & 8119 & - & - & \text { Tam }\end{array}$

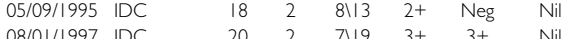

29/12/2003 IDC $\quad 15$ 3 $45145 \mathrm{Neg} \quad \mathrm{Neg}$ CT (FEC)

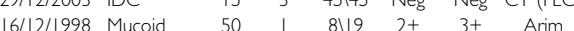

carcinoma

08/01/1999 IDC

01/01/2000 Multifo

$\begin{array}{cccccc}20 & 3 & 4126 & \mathrm{Neg} & \mathrm{Neg} & \mathrm{Nil} \\ 14 & 2 & 20139 & 3+ & 3+ & \text { Arim }\end{array}$

0.12
0.18
0.10
0.22

$\begin{array}{lll}0.10 & 0 & 143 \\ 0.22 & 3 & 108 \\ 0.03 & 0 & 123\end{array}$

$\begin{array}{rrr}0.25 & 2 & 77 \\ 0.11 & 1 & 125\end{array}$

$\begin{array}{lll}0.47 & 7 & 135\end{array}$

0.03
0.02

$0.02 \quad 1 \quad 135$

$0.14 \quad 0$

0.22

0.20

0.12
0.18
0.03

0.03

$\begin{array}{rrr}0.03 & 6 & 97 \\ 0.03 & 0 & 110\end{array}$

$0.06 \quad 0 \quad 132$

$\begin{array}{lll}0.02 \quad 0 \quad 10 \\ 0.06 & 0 & 0\end{array}$

$\begin{array}{ll}0.02 & 0 \\ 0.06 & 0 \\ 0.01 & 0\end{array}$

$\begin{array}{rrr}0.01 & 0 & 128\end{array}$

$\begin{array}{lll}0.08 & 0 & 102 \\ 0.00 & 0 & 119\end{array}$

0.10

$\begin{array}{lll}0.00 & 0 & 98 \\ 0.04 & 0 & 76\end{array}$

$\begin{array}{rrr}0.04 & 0 & 76 \\ 0.20 & 0 & 106\end{array}$

$\begin{array}{ll}0.20 & 1 \\ 0.32 & 0\end{array}$

$\begin{array}{ll}0.32 & 0 \\ 0.09 & 0\end{array}$

lobular
carcinom

Arim = arimidex; $\mathrm{BM}=$ bone marrow; $\mathrm{CT}=$ chemotherapy; $\mathrm{CTCs}=$ circulating tumour cells; DCIS = ductal carcinoma in situ; DTCs = disseminated bone marrow tumour cells; $\mathrm{ER}=$ oestrogen receptor; FEC = fluorouracil, epirubicin and cyclophosphamide; ICC = immunocytochemistry; IDC = infiltrating ductal carcinoma; ILC=infiltrating lobular carcinoma; $N D=$ not done; Neg = negative; PB = peripheral blood; Pos = positive; PR = progesterone receptor; QPCR = quantitative PCR; Tam = tamoxifen. High-risk patients therapy and monitoring details. Results for CTCs and DTCs in 33 group III high-risk primary breast cancer patients. 
in a metastatic cascade (Pantel and Brakenhoff, 2004; Pantel et al, 2008).

We have monitored patients with primary breast cancer using sequential bone marrow aspirates for several years. Although these results indicate that a proportion of patients have PCR or immunocytochemical evidence of micrometastases, the test is confounded by the problem of sampling errors and in disease variability. In our study (Slade et al, 2005), we followed up 131 primary breast cancer patients for 4 years after surgery with bone marrow aspirates; $73 \%$ showed a fall in the micrometastatic load as measured by PCR and $63 \%$ as determined by ICC during follow-up. Of 91 patients who had repeat samples assayed, 87 and $65 \%$ had positive results at some time using PCR and ICC, respectively.

Patients are reluctant to have bone marrow tests more often than every 6 months, and thus it is difficult to even repeat the test to see whether the result is consistent. The CellSearch system, requiring only a peripheral blood sample, can be used frequently during follow-up. Our results indicate that either CTC sampling or a combination of blood and bone marrow tests may provide a practical monitoring system for breast cancer patients on followup. In our experience, many patients find repeat bone marrow sampling difficult and painful; this study suggests that the number of CTCs found on blood sampling is similar to the number found in bone marrow samples. Thus, blood tests may, in the future, be used in place of bone marrow sampling. However, before this can be recommended, we believe that a prospective study should be done comparing both tests.

Others have shown that the persistence of DTCs after treatment indicates a poor prognosis. Braun et al $(1999,2000 \mathrm{a})$ investigated the effect of $500 \mathrm{mg}$ of Edrecolomab on bone marrow micrometastases in 10 primary breast cancer patients before and at days 5-7 after antibody treatment. They showed a reduction in the number of disseminated cells after therapy. We (Smith et al, 2000) analysed 145 blood samples obtained from 22 metastatic breast cancer patients, both by immunocytochemistry and PCR, over 13 months. Of the 25 assessable courses of treatment, PCR agreed with the clinical outcome in 17 cases $(68 \%)$ and ICC in 12 cases (48\%). When 356 disease-free patients (Wiedswang et al, 2003) were subsequently analysed with a second bone marrow aspirate

\section{REFERENCES}

Braun S, Hepp F, Kentenich CR, Janni W, Pantel K, Riethmuller G, Willgeroth F, Sommer HL (1999) Monoclonal antibody therapy with edrecolomab in breast cancer patients: monitoring of elimination of disseminated cytokeratin-positive tumor cells in bone marrow. Clin Cancer Res 5: 3999-4004

Braun S, Kentenich C, Janni W, Hepp F, de Waal J, Willgeroth F, Sommer H, Pantel K (2000a) Lack of effect of adjuvant chemotherapy on the elimination of single dormant tumor cells in bone marrow of high-risk breast cancer patients. J Clin Oncol 18: 80-86

Braun S, Pantel K, Muller P, Janni W, Hepp F, Kentenich CR, Gastroph S, Wischnik A, Dimpfl T, Kindermann G, Riethmuller G, Schlimok G (2000b) Cytokeratin-positive cells in the bone marrow and survival of patients with stage I, II, or III breast cancer [see comments]. $N$ Engl J Med 342: $525-533$

Braun S, Pantel K, Muller P, Janni W, Hepp F, Kentenich CRM, Gastroph S, Wischnik A, Dimpfl T, Kindermann G, Riethmuller G, Schlimok G (2000c) Cytokeratin-positive cells in the bone marrow and survival of patients with stage I, II, or III breast cancer. $N$ Engl J Med 342: $525-533$

Braun S, Vogl FD, Naume B, Janni W, Osborne MP, Coombes RC, Schlimok G, Diel IJ, Gerber B, Gebauer G, Pierga JY, Marth C, Oruzio D, Wiedswang G, Solomayer EF, Kundt G, Strobl B, Fehm T, Wong GY, Bliss J, Vincent-Salomon A, Pantel K (2005) A pooled analysis of bone marrow micrometastasis in breast cancer. $N$ Engl J Med 353: 793-802

Coombes RC, Hall E, Gibson LJ, Paridaens R, Jassem J, Delozier T, Jones SE, Alvarez I, Bertelli G, Ortmann O, Coates AS, Bajetta E, Dodwell D, after a 3-year follow-up, the presence of micrometastases at this stage in disease-free patients was shown to be an independent prognostic factor (Wiedswang et al, 2004). Stathopoulou et al (2003) used real-time RT - PCR to study 77 patients with primary breast cancer before and after adjuvant chemotherapy, and showed a marked reduction both in the number of positive patients (31.2$6.5 \%)$ and in the level of positivity. They also studied 47 patients with overt metastases before and after chemotherapy and found no differences either in the number of patients positive (40.4 and $42.6 \%)$ or in the levels of positivity. In a study of 228 patients followed up with a repeat bone marrow aspirate 21 months after diagnosis, Janni et al (2005) showed that recurrence-free survival in patients with no DTCs was 149.7 months compared with 86.5 months in patients positive for DTCs $(P=0.0003)$ and that overall survival was 162.1 months compared with 98.7 months $(P=0.0008)$, respectively.

Recently, the need for a monitoring system has been highlighted by several trials indicating that sequential treatment during the disease-free period may improve overall survival in breast cancer. Thus, the Inter-Group Exemestane Study (IES) and ArimidexNoluadex (ARNO)/Austrian Breast Cancer Study Group (ABCSG) studies both indicate that this approach may be preferable, as does the concept of sequencing chemotherapy, such as indicated by the studies using anthracyclines followed by taxanes. We feel that further adjuvant therapy during the follow-up period may yield better results, providing that these patients are selected on the basis of residual DTCs or CTCs.

\section{ACKNOWLEDGEMENTS}

We thank the funding support from the Breast Cancer Research Trust (JS, MJS), Cancer Research (UK) (RP and RCC) and European Commission (DISMAL-project, contract no. LSHC-CT2005-018911) to MJS, RCC and KP. The UK National Translational Network (NTRAC) (BW) and the Deutsche Krebshilfe, Bonn, Germany (KP). This work was funded in part by a grant from Veridex, LLC. We are very grateful to Mr Nils Taube and Mr David Beer for their support.
Coleman RE, Fallowfield LJ, Mickiewicz E, Andersen J, Lonning PE, Cocconi G, Stewart A, Stuart N, Snowdon CF, Carpentieri M, Massimini G, Bliss JM (2004) A randomized trial of exemestane after two to three years of tamoxifen therapy in postmenopausal women with primary breast cancer. N Engl J Med 350: 1081- 1092

Coombes RC, Kilburn LS, Snowdon CF, Paridaens R, Coleman RE, Jones SE, Jassem J, Van de Velde CJ, Delozier T, Alvarez I, Del Mastro L, Ortmann O, Diedrich K, Coates AS, Bajetta E, Holmberg SB, Dodwell D, Mickiewicz E, Andersen J, Lonning PE, Cocconi G, Forbes J, Castiglione M, Stuart N, Stewart A, Fallowfield LJ, Bertelli G, Hall E, Bogle RG, Carpentieri M, Colajori E, Subar M, Ireland E, Bliss JM (2007) Survival and safety of exemestane versus tamoxifen after 2-3 years' tamoxifen treatment (Intergroup Exemestane Study): a randomised controlled trial. Lancet 369: $559-570$

Cote RJ, Rosen PP, Hakes TB, Sedira M, Bazinet M, Kinne DW, Old LJ, Osborne MP (1988) Monoclonal antibodies detect occult breast carcinoma metastases in the bone marrow of patients with early stage disease. Am J Surg Pathol 12: 333-340

Cristofanilli M, Budd GT, Ellis MJ, Stopeck A, Matera J, Miller MC, Reuben JM, Doyle GV, Allard WJ, Terstappen LW, Hayes DF (2004) Circulating tumor cells, disease progression, and survival in metastatic breast cancer. $N$ Engl J Med 351: 781 -791

Cristofanilli M, Hayes DF, Budd GT, Ellis MJ, Stopeck A, Reuben JM, Doyle GV, Matera J, Allard WJ, Miller MC, Fritsche HA, Hortobagyi GN, Terstappen LW (2005) Circulating tumor cells: a novel prognostic factor for newly diagnosed metastatic breast cancer. J Clin Oncol 23: 1420 - 1430 
Diel IJ, Kaufmann M, Costa SD, Holle R, von Minckwitz G, Solomayer EF, Kaul S, Bastert G (1996) Micrometastatic breast cancer cells in bone marrow at primary surgery: prognostic value in comparison with nodal status [see comments]. J Natl Cancer Inst 88: 1652-1658

Hayes DF, Cristofanilli M, Budd GT, Ellis MJ, Stopeck A, Miller MC, Matera J, Allard WJ, Doyle GV, Terstappen LW (2006) Circulating tumor cells at each follow-up time point during therapy of metastatic breast cancer patients predict progression-free and overall survival. Clin Cancer Res 12: $4218-4224$

Janni W, Rack B, Schindlbeck C, Strobl B, Rjosk D, Braun S, Sommer H, Pantel K, Gerber B, Friese K (2005) The persistence of isolated tumor cells in bone marrow from patients with breast carcinoma predicts an increased risk for recurrence. Cancer 103: 884-891

Mansi JL, Gogas H, Bliss JM, Gazet JC, Berger U, Coombes RC (1999) Outcome of primary-breast-cancer patients with micrometastases: a long-term follow-up study. Lancet 354: 197-202

Meng S, Tripathy D, Frenkel EP, Shete S, Naftalis EZ, Huth JF, Beitsch PD, Leitch M, Hoover S, Euhus D, Haley B, Morrison L, Fleming TP, Herlyn D, Terstappen LWMM, Fehm T, Tucker TF, Lane N, Wang J, Uhr JW (2004) Circulating tumor cells in patients with breast cancer dormancy. Clin Cancer Res 10: $8152-8162$

Muller V, Stahmann N, Riethdorf S, Rau T, Zabel T, Goetz A, Janicke F, Pantel K (2005) Circulating tumor cells in breast cancer: correlation to bone marrow micrometastases, heterogeneous response to systemic therapy and low proliferative activity. Clin Cancer Res 11: 3678-3685

Naume B, Wiedswang G, Borgen E, Kvalheim G, Karesen R, Qvist H, Janbu J, Harbitz T, Nesland JM (2004) The prognostic value of isolated tumor cells in bone marrow in breast cancer patients: evaluation of morphological categories and the number of clinically significant cells. Clin Cancer Res 10: 3091 - 3097

Neville AM, Foster C, Redding H, Coombes RC (1983) Monoclonal antibodies as probes of human breast disorders. Ann NY Acad Sci 417: 251-261

Pantel K, Brakenhoff RH (2004) Dissecting the metastatic cascade. Nat Rev Cancer 4: $448-456$

Pantel K, Brakenhoff RH, Brandt B (2008) Detection, clinical relevance and specific biological properties of disseminating tumour cells. Nat Rev Cancer 8: $329-340$

Pantel K, Felber E, Schlimok G (1994) Detection and characterization of residual disease in breast cancer. J Hematother 3: 315-322

Pantel K, Schlimok G, Braun S, Kutter D, Lindemann F, Schaller G, Funke I, Izbicki JR, Riethmuller G (1993) Differential expression of proliferationassociated molecules in individual micrometastatic carcinoma cells. J Natl Cancer Inst 85: 1419-1424

Rack BK, Schindlbeck C, Janni WJ, Hofmann S, Jeschke U, ThurnerHermanns E, Hilfrich J, Beckmann MW, Pantel K, Lichtenegger W, Sommer H, Friese K (2006) Circulating tumor cells (CTCs) in peripheral blood of primary breast cancer patients. San Antonio Breast Cancer Symposium Poster Session V (Abstract 5007)
Redding WH, Coombes RC, Monaghan P, Clink HM, Imrie SF, Dearnaley DP, Ormerod MG, Sloane JP, Gazet JC, Powles TJ (1983) Detection of micrometastases in patients with primary breast cancer. Lancet 2: $1271-1274$

Riethdorf S, Fritsche H, Muller V, Rau T, Schindlbeck C, Rack B, Janni W, Coith C, Beck K, Janicke F, Jackson S, Gornet T, Cristofanilli M, Pantel K (2007) Detection of circulating tumor cells in peripheral blood of patients with metastatic breast cancer: A Validation Study of the CellSearch System. Clin Cancer Res 13: 920-928

Schoenfeld A, Kruger KH, Gomm J, Sinnett HD, Gazet JC, Sacks N, Bender HG, Luqmani Y, Coombes RC (1997) The detection of micrometastases in the peripheral blood and bone marrow of patients with breast cancer using immunohistochemistry and reverse transcriptase polymerase chain reaction for keratin 19. Eur J Cancer 33: 854-861

Slade MJ, Singh A, Smith BM, Tripuraneni G, Hall E, Peckitt C, Fox S, Graham H, Luchtenborg M, Sinnett HD, Cross NC, Coombes RC (2005) Persistence of bone marrow micrometastases in patients receiving adjuvant therapy for breast cancer: results at 4 years. Int J Cancer 114: $94-100$

Slade MJ, Smith BM, Sinnett HD, Cross NC, Coombes RC (1999) Quantitative polymerase chain reaction for the detection of micrometastases in patients with breast cancer. J Clin Oncol 17: 870-879

Smith BM, Slade MJ, English J, Graham H, Luchtenborg M, Sinnett HD, Cross NC, Coombes RC (2000) Response of circulating tumor cells to systemic therapy in patients with metastatic breast cancer: comparison of quantitative polymerase chain reaction and immunocytochemical techniques. J Clin Oncol 18: 1432-1439

Stathopoulou A, Gizi A, Perraki M, Apostolaki S, Malamos N, Mavroudis D, Georgoulias V, Lianidou ES (2003) Real-time quantification of CK-19 mRNA-positive cells in peripheral blood of breast cancer patients using the lightcycler system. Clin Cancer Res 9: 5145-5151

Stigbrand T, Andres C, Bellanger L, Bishr Omary M, Bodenmuller $\mathrm{H}$, Bonfrer H, Brundell J, Einarsson R, Erlandsson A, Johansson A, Leca JF, Levi M, Meier T, Nap M, Nustad K, Seguin P, Sjodin A, Sundstrom B, van Dalen A, Wiebelhaus E, Wiklund B, Arlestig L, Hilgers J (1998) Epitope specificity of 30 monoclonal antibodies against cytokeratin antigens: the ISOBM TD5-1 Workshop. Tumour Biol 19: 132-152

Wiedswang G, Borgen E, Karesen R, Kvalheim G, Nesland JM, Qvist H, Schlichting E, Sauer T, Janbu J, Harbitz T, Naume B (2003) Detection of isolated tumor cells in bone marrow is an independent prognostic factor in breast cancer. J Clin Oncol 21: 3469-3478

Wiedswang G, Borgen E, Karesen R, Qvist H, Janbu J, Kvalheim G, Nesland JM, Naume B (2004) Isolated tumor cells in bone marrow three years after diagnosis in disease-free breast cancer patients predict unfavorable clinical outcome. Clin Cancer Res 10: $5342-5348$

Wulfing P, Borchard J, Buerger H, Heidl S, Zanker KS, Kiesel L, Brandt B (2006) HER2-positive circulating tumor cells indicate poor clinical outcome in stage I to III breast cancer patients. Clin Cancer Res 12: $1715-1720$ 